M. Margarida Sobral Neto

\title{
INTRODUÇÃO E EXPANSÃO DA CULTURA DA BATATA NA REGIÃO DE COIMBRA (SÉCS. XVII-XIX)
}




\section{INTRODUÇÃO E EXPANSÃO DA CULTURA DA BATATA NA REGIÃO DE COIMBRA (SÉCS. XVII-XIX)}

1. Oriunda dos planaltos da América do Sul, a batata chegou à Europa no século XVI. Neste século e no seguinte o cultivo do tubérculo confinou-se a pequenos núcleos, excepto no caso da Irlanda, país onde se tornou desde cedo cultura principal. Crises agrícolas e de subsistências registadas no século XVIII em várias regiões europeias aceleraram a expansão da nova cultura. No século XIX a batata viria a integrar-se plenamente nos sistemas de cultivos, tornando-se alimento quotidiano de animais e pessoas, fundamentalmente das mais pobres ${ }^{1}$ ).

Em Portugal, a difusão da cultura da batata ocorreu nos finais do século XVIII ( ${ }^{2}$ ). Como aconteceu em outros países europeus, até

( ${ }^{1}$ Sobre a introdução e difusão da batata em diversos países da Europa ver: Redcliffe Salaman, The History and Social Influence of the Potato, Cambridge, 1985 (Reimpressão com uma nova introdução e correcções da autoria de J. G. Hawkes); Daniel Faucher, Geografia agraria, 2." ed., Barcelona, 1975, pp. 104-108; Michel Morineau, "Cendrillon devenue fée. La pomme de terre au XVIII siècle", em Pour une Histoire Économique vraie, Lille, 1985, pp. 121-139; Slicher van Bath, Historia Agraria de Europa Occidental.

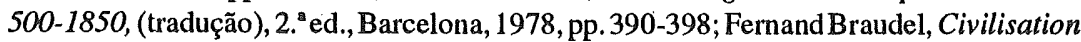
matérielle, Economie et Capitalisme. XVe-XVllle siècle, Armand Colin, t. I, Paris, 1979, pp. 139-143; De Papa a Patata. La difusión española del tubérculo andino, ed. Javier López Linage, Lunverg Editores, S . A., Madrid, 1991.

(2) Cfr. Manuel Viegas Guerreiro, "A cultura da batata, sua introdução na Europa. O 
a esta data o cultivo da nova planta deve-se ter confinado a alguns espaços dispersos $\left(^{3}\right)$.

Investigações por nós realizadas revelaram-nos um desses espaços.

2. A fonte em que encontramos registado o cultivo da batata é um documento da mesma natureza daqueles que têm sido utilizados pelos historiadores para conhecer a introdução do cultivo de plantas novas nos tradicionais sistemas de culturas, isto é, as fontes existentes em núcleos documentais da Igreja e/ou de Senhorios referentes à cobrança de tributos sobre a produção agrícola. $\mathrm{O}$ cultivo da batata tem sido revelado à medida que se vão explorando os núcleos documentais referentes à tributação agrária - fundamentalmente os registos de cobrança de dízimos - e os processos judiciais referentes a pleitos, entre entidades senhoriais e agricultores, motivados pela recusa do pagamento de encargos vários $\left({ }^{4}\right)$.

No nosso caso trata-se de um documento existente no núcleo documental do mosteiro de Santa Cruz de Coimbra, que nos informa sobre a exigência deste mosteiro de cobrança de uma parte

caso de Portugal", in Memórias da Academia das Ciências de Lisboa, Classe de Letras, t. XXVI, Lisboa, 1987, pp. 7-24.

$\left({ }^{3}\right)$ É provável que a batata já fosse cultivada em Trás-os-Montes nos inícios do século XVIII. Com efeito, Francisco da Fonseca Henriques informa-nos que "em algumas terras frias da Provincia de Traz-os-montes ha humas plantas, que se cultivão nas hortas, em cujas raizes se achão huns frutos redondos, á maneyra de tuveras da terra do tamanho de nozes grandes, \& algumas maiores, aos quaes chamão castanhas da India" (Anchora medicinal..., Lisboa, 1721, p. 317). (Agradecemos esta informação ao Senhor Professor Doutor Luís Ferrand de Almeida). Curiosamente, "castañas que llaman indias" era a designação atribuída às batatas, em meados do século XVIII, em municípios da Província de Orense. (Cfr. Maria Xosé Rodrígues Galdo, "Introducción y difusión del cultivo de la patata en España (siglos XVI-XVIII)", em De Papa a Patata. La difusión española del tubérculo andino, ob.cit, p. 93).

$\left({ }^{4}\right)$ Cfr. Fernand Braudel, Civilisation materielle, Economie et Capitalisme. XV.e-XVlll.e siècle, cit., t. I, p. 142. 
da produção de batata produzida em Quiaios, freguesia do actual concelho da Figueira da Foz.

É uma "carta citatória", datada de 16 de Março de 1643, enviada pelo conservador da Universidade de Coimbra, na qualidade de Juiz privativo do referido mosteiro, ao juiz do couto de Quiaios, em que se ordenava a citação de 32 moradores de aquele couto, que os Crúzios queriam demandar devido ao facto de "nam quererem paguar a setima parte das batatas que haviaõ nas terras do dito couto" ( $\left.{ }^{5}\right)$.

O convento tomava esta atitude na sua qualidade de "direito senhorio" $\left.{ }^{6}\right)$ de todo o couto, estatuto que Ihe dava o direito de receber uma parte de toda a produção agrícola, no caso "a setima parte de todas as novidades", conforme estava consignado no foral. O foral manuelino deste couto prescrevia o pagamento ao senhorio directo de uma ração de "sete huum" de "todo o pam, vinho, linho, alhos, cebollas, hervanços e de todollos legumes" colhidos nos terrenos "rotos" assim como naqueles "por romper" ().

Odocumento foi recebido pelo juiz do couto no dia 20 do mesmo mês. Nesta data o referido juiz mandou dar-lhe cumprimento. Na sequência desta ordem as pessoas constantes do rol foram citadas pelo porteiro do couto.

Em resposta à citação, compareceram perante o escrivão do couto, nos dias oito e nove de Abril, e disseram "que nam queriam demanda com seu senhorio" e por isso estavam dispostos a pagar a ração de sétimo das batatas, assim como pagavam das mais

$\left({ }^{5}\right)$ Cartacitatoria do conservadorda Universidade de Coimbra passada apedido dos religiosos do mosteiro de Santa Cruz de Coimbra pelos setimos das batatas, 6 de Março de 1643 (ANTT, SC, maço 24).

$\left(^{6}\right)$ "Direito senhorio" significava a posse do domínio directo sobre todo o espaço, cultivado e inculto, abrangido pelo couto. Este domínio traduzia-se, por exemplo, no direito de cobrar todas as prestações e tributos fixados em contratos de aforamento ou consignadas em foral.

( ${ }^{7}$ Luís Fernando de Carvalho Dias, Forais manuelinos do Reino de Portugal e do Algarve. Estremadura, Lisboa, 1962, p. 116. 
novidades que colhiam nas suas terras. Acrescentavam ainda que não queriam "justiça por serem homens pobres".

Uma das pessoas citadas, de nome António Ribeiro, enviou uma carta ao Prior de Santa Cruz afirmando que não tinha qualquer "duvida" em pagar a referida ração. Considerando-se um "leal cervo" de um mosteiro em relação ao qual tinha "tantas obrigaçoins", solicitava ainda "a caridade" de não procederem contra ele.

Perante a atitude de submissão dos produtores de batata, que preferiram aceitar o pagamento da ração a sujeitar-se aos custos da justiça, os religiosos não prosseguiram a demanda.

Os documentos acima referidos informam-nos, assim, que nos inícios da década de 40 do século XVII já se praticava em Quiaios o cultivo de um fruto denominado batata, cultivo que já ultrapassaria o espaço do jardim ou da horta. Com efeito, a análise do rol de pessoas citadas, que contém o nome dos produtores acompanhado do quantitativo de alqueires de batata sujeito a ração, informa-nos que o mosteiro exigia uma quota de uma produção de 1010 alqueires. O maior número de produtores (23) cultivava entre $40 \mathrm{e}$ 10 alqueires. Apenas um cultivava 80, dois 60 e outros dois 50 .

Como decorre do que foi dito podemos concluir que nos anos 40 do século XVII, as terras da serra de Quiaios ou as areias da gândara do mesmo lugar $\left(^{8}\right)$ (não temos elementos que nos permitam uma localização precisa) já acolhiam uma planta denominada batata.

Em aberto ficam várias perguntas a que as fontes analisadas, pela sua própria natureza, não podem dar resposta, tais como: data de introdução, proveniência da planta, variedade cultivada, utilização do fruto. Avançamos entretanto algumas hipóteses.

$\left({ }^{8}\right)$ O couto de Quiaios situava-se na vertente norte da serra da Boa Viagem, prolongando-se pela região da Gândara. Sobre a delimitação e caracterização geográfica da Gândara ver: Fernandes Martins, Le Centre Littoral etle massifcalcaire d'Estremadure, Lisboa, 1949, pp. 45-49; Fernanda Delgado Cravidão, A população e o povoamento da Gândara (génese e evolução), Coimbra, Comissão de Coordenação da Região Centro, 1992. 
O volume da produção de batata leva-nos a pensar que se tratava de uma planta com algum tempo de cultivo. O facto de o mosteiro accionar o processo judicial em 1643 pode explicar-se pelo facto de só nesta data ter tido conhecimento da cultura, conhecimento que poderá ter obtido através das investigações feitas pelo procurador do convento nas décadas de 20 e 30 do século XVII para a realização de tombos naquela zona $\left({ }^{9}\right)$. Como os produtores deste novo fruto se tivessem recusado, num primeiro momento, a repartir a colheita, do facto foi dado conta ao convento e foi-lhes movida demanda.

De notar que, nesta altura, foram detectadas outras situações irregulares em matéria de pagamento de direitos. De 1631 data outra sentença do conservador da Universidade condenando três moradores do couto de Quiaios a pagarem o "setimo" da fruta dos pomares, dos melões, abóboras, bem como de "todas as mais cousas que tivessem nas propriedades dentro do dito couto" $\left({ }^{10}\right)$.

A existência de um foco, ainda que restrito, de cultivo da batata nas terras magras do couto de Quiaios, nas primeiras décadas do século XVII, pode compreender-se à luz do que sabemos sobre a introdução da planta e sobre os factores que terão levado à criação de hábitos de consumo deste tubérculo. Em várias regiões da Europa os tempos de guerra, de fome e de carestia de cereais foram tempos propícios à propagação de um fruto que se dava bem em solos pobres e servia de substituto para o pão $\left({ }^{11}\right)$. Também na região de Coimbra o incentivo ao cultivo da batata pode ter sido dado nos anos de más colheitas e de consequente carestia cerealífera ocorridos nas primeiras décadas do século XVIII $\left({ }^{12}\right)$.

$\left({ }^{9}\right)$ Cfr. M. Margarida Sobral Neto, Regime Senhorial, Sociedade e Vida Agrária. $O$ Mosteiro de Santa Cruz e a região de Coimbra (1700-1834), tese de doutoramento policopiada, Coimbra, 1991, vol. I, pp. 26-44.

$\left({ }^{10}\right)$ Cfr. M. Margarida Sobral Neto, ob. cit., vol. I, p. 138.

(11) Cfr. M. Morineau, cit.

(12) António de Oliveira, A vida económica e social de Coimbra de 1537 a 1640, vol. 
Outra pergunta que se coloca é a relativa à forma como chegou a batata a Quiaios. Uma hipótese é a via marítima. Temos várias notícias de restos de naufrágios que chegavam ao tempo à costa de Quiaios $\left({ }^{13}\right)$. Manuel Viegas Guerreiro coloca a hipótese de as batatas terem chegado a Portugal, em fins do século XVI, vindas da Galizal $\left({ }^{14}\right)$. Na verdade, no século XVII, o tubérculo era conhecido em diversos pontos do Noroeste Peninsular, sendo, no entanto, o seu cultivo "apenas esporádico experimental" ( $\left.{ }^{15}\right)$.É uma hipótese ainda em aberto que as batatas tivessem chegado a Quiaios provenientes de um navio naufragado.

Quanto à variedade existente em Quiaios nada podemos adiantar, por não haver nos documentos qualquer referência que permita a sua identificação.

3. De 1730 data o segundo documento que nos permite acompanhar a evolução do cultivo da batata. Trata-se mais uma vez de um libelo apresentado contra moradores de Quiaios que se recusavam de novo a pagar ração de batata $\left({ }^{16}\right)$.

O texto do libelo informa-nos que os produtores de batata de Quiaios terão pago ração ate 1692 . A partir desta data, os rendeiros

II, Coimbra, 1971, pp. 174-180; Frédéric Mauro, Portugal, o Brasil e o Atlantico. 15701670, vol. II, Editorial Estampa, Lisboa, 1988, pp. 67-73.

$\left({ }^{13}\right)$ No tombo realizado na primeira metade do século XVII foi registado o direito do mosteiro de Santa Cruz, direito confirmado pelo procurador do concelho e por três homens antigos, às "naus e quaisquer outras cousas que com ellas fazendo naufragio sahirem na costa de Quiaios". Os materiais provenientes de naufrágios eram recolhidos na quinta da Fonte Quente, lugar onde os proprietários os podiam reivindicar (AUC, SC, Liv.83, f. 815-817).

$\left({ }^{14}\right)$ Manuel Viegas Guerreiro, cit., p. 7.

${ }^{(5)}$ Maria Xosé Rodrígues Galdo, "Introducción y difusión del cultivo de la patata en España (siglos XVI-XVIII)", em De Papa a Patata. La difusión española del tubérculo andino, ob.cit., p. 92.

$\left({ }^{16}\right)$ Sentença civel passada a requerimento do Prior Geral....contra o capitão Manuel Cardozo da Maia....e outros muitos moradores do couto de Quiaios (ANTT, SC., maço 24). 
deixaram de cobrar o referido encargo. $O$ atraso no accionar de uma nova demanda foi justificado pelos Crúzios invocando a distância de "sete legoas" que separava o convento do couto de Quiaios e o facto de a renda ser cobrada por rendeiros que não tinham informado a casa senhorial.

A deteç̧ão desta irregularidade, nesta data, deve-se também, segundo pensamos, às investigações que estavam a ser feitas na altura para a realização dos tombos de Maiorca e Alhadas. Outros factores terão concorrido para que os frades estivessem particularmente atentos ao que se passava em Quiaios. Entre eles destaca-se uma demanda que corria então entre os oficiais concelhios deste couto e Santa Cruz motivada pelas divergências relativas à administração de terras incultas $\left({ }^{17}\right)$.

É ainda de admitir uma terceira hipótese. Os arrematantes das rendas senhoriais eram os responsáveis directos pela cobrança de dízimos e rações. Ora, nas primeiras décadas do século, a renda de Quiaios fora arrematada por rendeiros de Quiaios e Redondos. Em 1728 e 1732, Manuel de Sousa Coelho, homem de negócio do Porto, arrematou a cobrança desta renda, afastando os cobradores locais. Este negociante aumentara os lanços e estava, naturalmente, interessado em "obter lucros e não perdas". Atendendo a estes factos, é 1ógico supor que tenha recorrido a todos os meios para repartir com rigor todas as produções agrícolas.

Do libelo agora apresentado ao juiz privativo constam 43 foreiros, que, segundo os Crúzios, cultivavam "várias sementeiras de batatas de que se alimentavam e utilizam (sic) suas cazas e familia como de outros quaisquer frutos e legumes".

Dado que, segundo os cálculos dos frades, estes enfiteutas colheriam "hum anno por outro quinze alqueires", os Crúzios alegavam que os cultivadores de batata deveriam pagar dois alquei-

$\left({ }^{17}\right)$ Cfr. M. Margarida Sobral Neto, ob. cit., vol. 1, pp. 112-122. 
res de ração para "alem do dizimo" $\left({ }^{18}\right)$. Alegavam ainda que do não pagamento da ração da batata advinha um grande prejuízo à renda senhorial dado que "as ditas batatas as cultivam e fabricam os Reos nas terras mais capazes de dar milho e outra qualquer novidade". Os frades consideravam, ainda, que da parte dos produtores havia ma fé, já que faziam a mudança de fruto "com dollo e malicia de se izentarem da dita reçam e dizimo".

Dando sequência a este pedido, foram enviadas cartas de citação para Maiorca, Alhadas e Quiaios, lugares onde habitavam os produtores.

A importância do assunto e a qualidade de algumas pessoas envolvidas (de salientar que a encabeçar a lista dos cultivadores de batata vinha um capitão) motivaram uma reunião da câmara do couto de Quiaios para deliberar sobre o assunto. A reunião, realizada em 19 de Dezembro de 1730, foi requerida "pella mayor parte do povo", que tinha sido citado. ("Por ser cauza que tocava com o dito povo queriam se ajustasse em camara"). Reunidos "o Juiz vereadores procurador do concelho do coutto de Quiaios com as pessoas principais e mayor parte do povo", decidiram aceitar o pagamento da ração das batatas e, por isso, não contestaram judicialmente o libelo. Da acta não constam as razões que os levaram a tomar esta atitude. Limitaram-se a dizer em relação ao libelo: "tudo Confessamos". A acta foi assinada pelos oficiais do concelho, pelo capitão Manuel Cardoso e por mais 46 casais. Em seguida, fixaram o dia para fazer a partilha e convocaram os Crúzios para assistir.

Em 2 de Abril, os procuradores dos foreiros deslocaram-se a Coimbra para dar conta da decisão tomada em câmara. No dia seguinte, o conservador aceitou a desistência.

Como decorre do atrás explanado, nas primeiras décadas do século XVIII continuava a praticar-se em Quiaios a cultura da

$\left({ }^{18}\right)$ O mosteiro de Santa Cruz de Coimbra, na sua qualidade de padroeiro da igreja de S. Mamede de Quiaios, tinha direito à cobrança de dízimos naquele couto. 
batata, cultura que assumia uma importância tão grande na vida da comunidade que levou à realização de uma reunião da câmara para tratar de assuntos com ela relacionados.

Os Crúzios argumentavam que os foreiros substituíam os campos de milho por campos de batata para fugirem à tributação que recaía sobre aquele cereal. Na verdade, a mudança de culturas foi uma estratégia usada pelos agricultores para fugirem aos tributos. Mas, neste caso, a batata não seria cultivada apenas em campos que anteriormente tinham sido de milho. Muitos seriam incultos. Com efeito, ao tempo assistia-se na Gândara ao arroteamento de terras, fenómeno em parte associado ao afluxo de gentes de localidades próximas ou mais longínquas, caso do Norte e do Litoral $\left({ }^{19}\right)$. E, como sabemos, a expansão do cultivo da batata acompanhou em algumas regiões o aumento da população $\left({ }^{20}\right)$.

4. Na primeira metade do século XVIII desenrolaram-se vários conflitos ente o mosteiro de Santa Cruze as pessoas que trabalhavam a terra integrada na área do seu domínio directo, conflitos que se desenrolaram noutros espaços da Gândara, Bairrada e Baixo Mondego $\left({ }^{21}\right)$. Todavia, pleitos motivados pela cultura da batata aparecem-nos apenas em Quiaios. Estaria a cultura da batata confinada apenas a este couto da Gândara?

Para meados do século possuímos informações relativas às plantas cultivadas em outras freguesias da região de Coimbra. São as prestadas pelos párocos em 1758. No entanto, na região da Gândara, Bairrada e do Baixo Mondego o único pároco que registou o cultivo da batata foi o de Brenha, lugar situado na Serra

$\left({ }^{19}\right)$ Sobre a ocupação e povoamento da Gândara ver: Fernanda Delgado Cravidão, A população e o povoamento da Gândara (génese e evolução), Coimbra, Comissão da Coordenação da Região Centro, 1992, pp. 64-119.

$\left({ }^{20}\right)$ Sobre a relação existente entre introdução da batata nos sistemas de cultivo e alimentar e crescimento demográfico cfr. M. Morineau, cit.

${ }^{(21)}$ M. Margarida Sobral Neto, ob.cit., vol.1, pp. 109-176. 
da Boa Viagem e confinante de Quiaios.

De notar, porém, que este pároco referiu o cultivo da batata a par do milho, trigo, cevada, vinho, feijões e cebolas, acrescentando que todas estas culturas produziam com pouca abundância por as terras serem "asperas" $\left({ }^{22}\right)$. Por sua vez, o pároco de Quiaios informou que os frutos que se recolhiam com "mais abundancia" na área da sua freguesia eram o milho grosso, o trigo, a cevada, os feijões e o vinho $\left({ }^{23}\right)$. Esta informação pode significar que a produção da batata era pouco abundante, comparativamente às outras referidas. Hipóteses a considerar são ainda o abandono temporário da cultura devido ao peso da tributação e uma eventual cumplicidade do pároco com os fregueses.

Em Brenha, a cultura da batata aparece-nos num dos seus contextos típicos: terra pobre, economia de subsistência baseada numa policultura e elevada densidade populacional $\left({ }^{24}\right)$.

5. A promoção da cultura da batata foi uma das vias defendidas pelos fisiocratas para o aumento da produção e da produtividade agrícolas e uma das soluções preconizadas para a resolução das crises agrícolas. Também os pensadores portugueses que se debruçaram sobre os problemas da agricultura nacional assumiram a defesa da integração da cultura da batata no sistema de cultivos.

Alguns defenderam a cultura nos terrenos pobres, destinada fundamentalmente à alimentação de animais. Foi o caso de Luís Ferrari Mordau. Este autor, na obra Despertador da Agricultura, escreveu: "Alem destas ervas [luzerna], ha muitas raizes de que gosta o gado, e o engorda muito, como são as batatas, e os rabos,

(22) ANTT, Memorias Paroquiais, vol.7, mem.65.

$\left({ }^{23}\right)$ ANTT, Memorias Paroquiais, vol.38, mem. 12.

(24) Em 1801 Brenha era uma localidade que registava uma das mais elevadas densidades populacionais da região de Coimbra (4,89 habitantes por fogo). (Cfr. Guilhermina Mota, "Estruturas familiares no mundo rural. Grupos domésticos no bispado de Coimbra em 1801", sep. da R.P.H., t. XXIV, Coimbra, 1990, pp. 15-16). 
nabos, fournips, toupinam, manhocas, e caçavas das Americas, e as batatas, que igualmente servem para a gente, em lugar de pão como fazem em Irlanda, darião grandissimas searas nas terras ligeiras, e arientas, que sendo inferiores para trigo são perfeitas para esse outro fruto, e este para os porcos tão excelente como as belotas, como tãobem o tem experimentado no Alem Tejo o mesmo Intendente da Agricultura" $\left({ }^{25}\right)$.

Por sua vez, João Manuel de Campos e Mesquita, autor que atribuía a insuficiente produção cerealífera "ao mau estado da cultura por falta de gados" $\left({ }^{26}\right)$, advogava como solução para 0 aumento da criação de gado vacum a promoção da "cultura de pastagens, e a de batatas" $\left({ }^{27}\right)$. Aqui a batata aparece como uma das soluções para uma melhor articulação e complementaridade entre agricultura e criação de gado estabular, função que aliás esta cultura desempenhou em alguns espaços.

$\mathrm{O}$ mesmo autor associaria também a descida do preço dos cereais registada na Beira, nos inícios do século XIX, à difusão da cultura da batata. "A guerra de 1762 fez na Beira diminuir as colheitas, e as criações do gado; crescendo o preço do pão: e este não veio a baixar senão em 1803, ano em que se fez muito geral a cultura das batatas" $\left({ }^{28}\right)$.

A promoção da cultura da batata como forma de resolução do problema da carestia dos cereais, e consequente clima de instabilidade social daí decorrente, foi assumida também pelas autoridades do tempo. Persuadir os camponeses a introduzir o cultivo da batata foi uma das missões atribuídas aos corregedores de Coimbra, desde

$\left({ }^{25}\right)$ Dom Luis Ferrari de Mordau, DespertadordaAgricultura de Portugal, publicado por Moses Bensabat Amzalak, Lisboa, 1951, p. 67.

$\left({ }^{26}\right)$ João Manuel de Campos e Mesquita, "Extracto da memória sobre o gado vacum", Memórias Económicas da Academia Real das Sciencias de Lisboa, t. IV, Lisboa, 1991, p. 316.

$\left({ }^{27}\right) 1$ dem, p. 317.

$\left({ }^{28}\right)$ lbidem, p. 316 . 
o início do século, quando faziam correições $\left({ }^{29}\right)$. De notar que o mesmo fenómeno ocorria ao tempo na Galiza $\left({ }^{30}\right)$.

A batalha dos pensadores e dos homens do poder no sentido da promoção da cultura da batata deparava, porém, com um forte obstáculo: a pesada tributação que sobre ela recaía.

$\mathrm{Na}$ Galiza, na segunda metade do século XVIII, os conflitos entre produtores de batata e perceptores de dízimos multiplicaram-se, arrastando-se algumas demandas até finais do século $\left({ }^{31}\right)$. Fenómeno semelhante ocorreu na região da Gândara. Aqui, os agricultores, apoiados agora por juristas, tentaram resistir nos campos e nos tribunais ao que consideravam abusos dos Senhores. Por sua vez as partes em conflito tiveram necessidade de apresentar elaborada argumentação no sentido de defenderem as suas posições $\left({ }^{32}\right)$. A registar esta luta ficaram documentos mais ricos em informa-ções relativas a vários aspectos da vida agrária.

A Gândara, em geral, e o couto de Quiaios em particular eram zonas particularmente controladas. Uma das explicações residirá na presença da Quinta da Fonte Quente $\left({ }^{33}\right)$, reserva senhorial do mosteiro, que funcionava como um posto de vigilância dos frades. A apertada vigilância que se verificava neste espaço compreende-se melhor se tivermos em conta que a Gândara possuía ainda espaços incultos que estavam a ser desbravados e transformados em campos de cultivo, por vezes de batata, à revelia dos religiosos.

Testemunha-nos este facto uma sentença do conservador da Universidade, datada de 1798, condenando alguns habitantes de Quiaios a abandonarem terras ocupadas nas imediações da Quinta

$\left.{ }^{(29}\right)$ Arquivo Municipal de Coimbra, Correições, 1795-1814.

$\left({ }^{30}\right)$ Maria Xosé Rodrigues Galdo, cit., p. 99.

${ }^{(31}$ ) ldem, p. 93.

$\left({ }^{32}\right)$ Sobre a contestação anti-senhorial na Gândara nos finais do séc. XVIII ver: M. Margarida Sobral Neto, ob. cit., vol. II.

$\left({ }^{33}\right.$ ) A quinta da Fonte Quente situava-se na freguesia de S. João da Quintã, isento do mosteiro de Santa Cruz de Coimbra, hoje freguesia da Tocha. 
da Fonte Quente. Sem autorização dos frades, estes homens derrubaram um valadoque protegia a quinta, fizeram uma queimada para preparar o terreno e semearam depois batatas $\left({ }^{34}\right)$.

Entretanto, os agricultores de Quiaios persistiam na recusa de pagamento de direitos sobre a cultura da batata. Em 1802 o mosteiro apresentou um libelo acusando os foreiros de se recusarem a pagar a ração e o dízimo daquela cultura, que, no dizer dos frades, ultrapassava já as necessidades de consumo familiar para assumir uma expressão comercial:

"A cultura das Batatas no terreno do couto de Quiaios he tao frequente, tao grande e tao universal, que os reos moradores no mesmo couto, costumao vender muitas e conduzem outras as feiras de Montemor, a outras partes e ainda a villa da Figueira para dali se transportarem em Navios para outras terras de sorte que as batatas formao naquelle couto, hum dos primeiros ou o principal ramo do Comercio; como he publico e notorio ainda as pessoas existentes fora do couto $\left({ }^{35}\right)$.

Não temos conhecimento de outras fontes que nos possam informar sobre a dimensão desta cultura e assim aferir da credibilidade do testemunho do senhorio. A escassez e carestia de cereais que ocorria ao tempo, e consequente necessidade de encontrar pão de substituição, era de molde a estimular a expansão de uma cultura num espaço que reunia boas condições para o seu cultivo (destacamos a experiência adquirida e a natureza adequada dos solos).

Como vimos, a atitude assumida pelos cultivadores de batata no século XVII e primeira metade do XVIII foi a aceitação formal das exigências senhoriais, evitando assim o prosseguimento das demandas. Mas agora o tempo já não era de submissão. Pelo contrário, era de contestação quase generalizada. Nesta conjuntura os produtores

$\left({ }^{34}\right)$ ANTT, SC., maço 153, doc. 14.

(35) Libelo contra os de Quiaios para pagarem a ração e dízimo das batatas, (ANTT, $\mathrm{SC}$, maço 153, doc.19). 
de batata recorreram a um advogado para os defender.

Este aduziu um conjunto de factos relativos à natureza da planta bem como a sua forma de integração no sistema de cultivos, factos ou meros argumentos utilizados para apoiar a subtracção da cultura aos direitos senhoriais. Assim, em relação ao argumento dos Crúzios segundo o qual as batatas ocupavam terras que podiam dar outras culturas, o jurista contrapunha que elas eram cultivadas em terrenos que já tinham produzido culturas tributadas, como eram os campos de linho ou os restolhos da cevada, do centeio ou do trigo. Alegava ainda que a batata constituía uma produção diferente daquelas cuja partilha se fazia na eira, comparando-a às plantas forrageiras como o nabo $\left({ }^{36}\right)$, "as batatas sam frutos criados debaixo da terra como raizes para milhor coltivação das mesmas terras, e darem e produzirem os outros frutos de que se pagam os direitos do costume", e ainda às abóboras, melancias e maçãs, frutos que se comiam em verde e que pagavam apenas o que os produtores ajustavam com o pároco.

Em apoio da sua argumentação afirmava ainda que os terrenos com produção de batatas em dois anos seguidos davam depois com mais abundância outros frutos, apresentando como exemplo o facto de a renda de Quiaios ter triplicado no período de 24 anos antecedentes, apesar de não se pagar ração e dízimo da batata.

Perante esta argumentação surge-nos a pergunta: ela seria baseada em factos reais ou nos textos dos pensadores que advogavam a difusão do cultivo da batata? A verificar-se a primeira hipótese, esta planta desempenharia nas terras da Gândara uma função que desempenhou em outros espaços. Com efeito, a integração do

${ }^{(36}$ ) Interessante notar que em 1800 os lavradores da paróquia de Santiago de Bravos, situada na Galiza, no actual concelho de Burgos, eram condenados ao pagamento do dízimo da batata. Estes escusavam-se com o mesmo argumento. (Cfr. Maria Xosé Rodriguez Galdo e Fausto Dopico G. de Arroyo, "Novos cultivos e cultura tradicional: a pataca en Galicia nos seculos XVIII e XIX", Revista Galega de Estudios Agrarios, n. ${ }^{\circ} 3,1980$, p. 22). 
cultivo da batata nos tradicionais sistemas de cultivo permitiu, em alguns lugares, uma diversificação de culturas e a rotação das mesmas, possibilitando assim a supressão do pousio e a consequente melhoria das condições de renovação da fertilidade da terra.

Nos finais do século XVIII a cultura da batata assumia também uma grande expressão no vizinho couto de Cadima. O facto é-nos mais uma vez revelado através do processo judicial relativo a uma demanda entre Santa Cruz e os foreiros de Cadima, que mostra as divergências quanto às culturas sujeitas a tributação senhorial.

Assim, enquanto os foreiros pretendiam pagar apenas ração de oitavo do pão, vinho e linho e nunca das cebolas e alhos e "outros generos semelhantes" e "indispensaveis ao uso do Lavrador", os Crúzios exigiam "ração de seis hum de todas as novidades". Ora, nesta "generalidade" compreendia-se, segundo os religiosos, o azeite, os legumes de que sempre se pagara ração e as batatas, "em que ha annos consiste huma grande (por não dizer principal) cultura daquellas terras" $\left({ }^{37}\right)$.

De notar que mais uma vez as informações relativas ao cultivo da batata são dadas pelo mosteiro, facto que se poderá explicar pela tentativa de ocultação e consequente fuga a partilha de uma cultura "indespensavel ao uso dos lavradores".

6. Nos inícios do século XIX, os solos do couto de Verride começaram a acolher o tubérculo confinado até aí aos terrenos montanhosos das encostas da Serra da Boa Viagem ou aos arenosos da Gândara.

Em resposta à pergunta relativa às culturas praticadas neste couto, contida num inquérito enviado pelo Provedor de Coimbra, em 1814, os moradores deste lugar responderam:

"A batata principia agora u ser hum obgeto porque como o pam chegou os annos proximos a hum presso exorbitante e o numerario

$\left({ }^{37}\right)$ Cfr. M. Margarida Sobral Neto, ob. cit., vol. II, p. 308. 
deminuio conçederavelmente os povos tornaramse as Batatas que The servem de pam e como desta qualidade de serial se não paga nem o dizimo porque os povos estam nesie custume todos plantam as batatas" $\left({ }^{38}\right)$.

Perante a carência de milho e trigo, os moradores de Verride recorreram assim ao cultivo de uma nova planta para substituirem o pão, tomando uma atitude de defesa habitual nos homens do campo em tempos de escassez ecarestia de cereais. A extensificação do cultivo da batata dos solos mais pobres para solospróximos, mas mais ricos, foi um fenómeno que ocorreu noutros espaços europeus em tempos de carência de pão $\left.{ }^{(39}\right)$.

Quanto ao facto de a cultura não pagar ração nem dízimo, ele só poderá explicar-se por desconhecimento do mosteiro de Santa Cruz, senhorio deste couto, ou pela inexistência de condições para exigir o pagamento.

Em Quiaios, zona muito afectada também pelas invasões, os Crúzios continuavam, entretanto, a exigir o pagamento. Em 1814, os produtores de batata recusavam-se, de novo, a pagar a ração. Sabemo-lo através de um pedido que o capitão José Pessoa e o alferes Francisco Gil Marques, cobradores da renda neste couto, fizeram ao convento para lhes ser abatido um terço do montante ajustado, pelo facto de a recusa ter surgido depois da realização do f. 24.

$\left({ }^{38}\right)$ Arquivo da Câmara Municipal de Montemor-o-Velho, Vereações, Verride, 1814,

$\left({ }^{39}\right)$ "Por todo o lado e sempre, a batata chegava nos vagões da miséria: guerras inglesas na Irlanda, guerras dos Trinta Anos e guerras de Luís XIV na Alsácia e na Lorena, guerra da Sucessão de Espanha, na Flandres e na Espanha, catástrofes cerealíferas do fim do século XVIII acrescidas, no Saxe, em 1770, de um conflito armado, em França com a desorganização civil da Revolução" (Michel Morineau, "Cendrillon devenue fee. La pomme de terre au XVIII siècle", cit., p. 127). Na Galiza, a crise de 1768-69 e a dos finais do século, levou também a uma intensificação do cultivo da batata. (Maria Xosé Rodriguez Galdo e Fausto Dopico G. de Arroyo. cit). Sobre a difusão da cultura da batata como "cereal" de substituição: Slicher van Bath, "HistoriaAgraria de Europa Occidental. 500-1850, cit., pp. 390-398; Fernand Braudel, Civilisation matérielle, Economie et Capitalisme. XV.e-XVlll.e siecle, cit., t. I, pp. 139-143. 
contrato de arrendamento. O mosteiro acedeu. Não foi, entretanto, bem sucedido na tentativa de fazer cobrança directa da ração e dízimo. "Os Povos se Levantarão, e não quiserão pagar antes espancarão o Verdeal que foi fazer a deligencia" $\left({ }^{40}\right)$.

Em 1815 os ânimos já tinham acalmado e o dízimo e a ração da batata entravam de novo no contrato. Mas, segundo testemunho de Fernandes Tomaz, tratou-se de uma aceitação compulsiva perante a intervenção de uma força militar presente no vizinho couto das Alhadas. Aceitação compulsiva e momentânea, pois as resistências ao pagamento da ração da batata não acabaram. Em 1819 e 1820 a arrematação da ração daquela cultura foi feita em separado e apenas pelo período de um ano, enquanto a da restante renda o foi por quatro anos, facto que pode significar a continuação de falta de confiança dos rendeiros na arrecadação desta prestação.

A intransigência dos Crúzios em relação à cobrança de uma pesada carga tributária levou, no dizer de Fernandes Tomaz, a um abandono da Gândara. Na sessão das Cortes de 3 de Novembro de 1821, este autor advogou a velha reivindicação dos moradores de Quiaios: a libertação da batata do pagamento da ração de sétimo e denunciou as "violências" cometidas pelos Crúzios contra os gandareses:

"Eu tenho sido testemunha de um facto que vou dizer, para que todos saibam. Todo o mundo sabe que no tempo de D. Manuel não havia batatas. Os frades Cruzios foram desenterrar, não sei como, nos forais, que tinham direito a cobrar batatas; os povos que faziam disto a maior sustentação e que daquelas terras em que o vento faz mudar todos os dias a ternperatura não podia tirar outro produto senão aquele fruto e que por isso as cultivam, foram enfim condenados a pagar batata aos frades, não só naquele tempo e para o futuro, senão pelo tempo pretérito. Eque se seguiu daqui?

$\left({ }^{40}\right)$ AUC, SC, t.49, Liv. 169, f.178. 
Ir uma alçada com um oficiale soldados armados e assolar aqueles povos, que se achavam sem resistência, e ultimamente perder $e$ arruinar aquelas terras em que se cultivava o único produto que se podia cultivar, pois os infelizes moradores desampararam a província: porque como todos os seus bens não consistiam mais que numa gamela e numa enxada, pegaram nela às costas e foram a outra parte" $\left({ }^{41}\right)$.

Os moradores de Vila Franca de Arazede, outro lugar da Gândara, em petição enviada às cortes liberais, fizeram acusações do mesmo teor aos Padres Bernardos. O Juiz, procurador e povo deste lugar afirmaram que "sómente á força de grandes despezas em estrumes, de munta industria e trabalho dos habitantes" conseguiam cultivar "nos frios e estéreis areaes da gandara" a batata, "unico alimento, de que elles se sustentão a maior parte do anno, e algum milho mas pouco". Criticavam deste modo a insaciavel ambição" dos religiosos de S. Bernardo de Coimbra, por exigirem ração de oitavo de todos os frutos, laudémio e o foro de uma galinha por jeira. Queixaram-se ainda "das demandas injustas em juizos privativos aonde a maior parte dos moradores não podem, por sua pobreza allegar sua justiça e defender-se", demandas que já tinham levado mais de 200 habitantes a abandonar as suas casas e os lavradores abonados a verem-se reduzidos "á pobreza e mizeria" ${ }^{42}$ ).

Odespovoamento da Gândara, provocado pela pesada tributação senhorial, testemunhado em Quiaios por Manuel Fernandes Tomaz, foi, deste modo, confirmado pelos moradores de Vila Franca de Arazede. Outras fontes atestam esta fuga dos gandareses que partiram à procura de terras mais livres da pressão senhorial.

Uma das zonas para onde se deslocaram as gentes da Gândara

(41) Documento publicado por José Tengarrinha em Manuel Fernandes Tomás. A Revolução de 1820, Lisboa, 1974, p. 144.

${ }^{\left({ }^{42}\right)}$ Albert Silbert, Le Probleme agraire portugais au temps des premieres Cortes libérales (1821-1823), 2.' ed., Paris, 1985, pp. 322-324. 
e dos Campos de Coimbra foi a região de Setúbal $\left({ }^{43}\right)$. Segundo testemunho do Juiz de Fora deste lugar o modo de vida da população da Vila da Moita alterou-se no período que decorreu de 1794 a 1798. Atribuía a mudança à deslocação para aquela vila de "algumas familias dos Campos de Coimbra" que aforaram várias porções de paúis e aí semearam batatas, depois de os terem arroteado e enxuto. Segundo aquele magistrado, a introdução desta cultura foi responsável por um aumento da população naquela região. A mesma fonte informa-nos ainda que a divulgação da planta na comarca de Setúbal foi, entretanto, entravada pelos tributos que passaram a ser exigidos aos produtores, neste caso os exigidos pelos rendeiros das sisas $\left({ }^{44}\right)$.

As invasões francesas, ao agravarem as condições de vida já de si difíceis, levaram outros gandareses à procura de outras terras. $\mathrm{O}$ Visconde de Balsemão, na Memória sobre a descrição física, $e$ económica do lugar da Marinha Grande, e suas vizinhanças dá a seguinte informação sobre as culturas praticadas naquela zona: "Além destes géneros (cereais), cultivam-se também plantas próprias para os gados, como o trevo e luzerna; fazem-se grandes nabais, e batatais, para os quais a terra é sumamente apropriada, e cuja cultura se tem adiantado muito, depois que algumas famílias de além Mondego, costumadas a este cultivo, ali se vieram estabelecer pela invasão de $1810^{\prime \prime}\left({ }^{45}\right)$.

A Gândara foi, assim, um centro difusor da cultura da batata, sendo esta transportada no farnel dos mais pobres para outras zonas do país.

( ${ }^{43}$ ) Cfr. M. Margarida Sobral Neto, ob. cit., vol. II, p. 276.

$\left({ }^{44}\right)$ Cfr. David Justino, A Formação do espaço económico nacional. Portugal, 1810 -1913 , vol. 1, Lisboa, s.d., pp. 41-42.

$\left({ }^{45}\right)$ Visconde de Balsemão, "Memória sobre a descrição física, e económica do lugar da Marinha Grande, e suas vizinhanças", em Memórias Económicas da Academia Real das Sciencias de Lisboa, t. V, Lisboa, 1991, p. 210. 
8, Segundo David Justino, em meados do século XIX, a cultura da batata isolava-se "em núcleos regionais de pequena extensão" $\left({ }^{46}\right)$. Este historiador apoia a sua afirmação em vários testemunhos, nomeadamente no de Manoel Teixeira Cabral de Mendonça. Escreveu este autor na segunda década do século XIX: "A cultura da batata, meio tão excellente de supprir os cereaes, está reduzida a certo número de destrictos: causará admiração ser ella totalmente desconhecida huma legoa ao Nascente de Coimbra, quando para Poente, e Norte desta Cidade o uso de cultivar as Batatas he talvez o mais geral do Reino" $\left.{ }^{47}\right)$.

Ao longo do século XIX a cultura da batata, mais liberta da tributação senhorial que a asfixiava, difundiu-se pelo distrito, tornando-se "o artigo principal na sustentação do povo trabalhador" $\left({ }^{48}\right)$.

Na década de 60 do século XIX a planta estava disseminada por todos os concelhos do distrito de Coimbra, registando, no entanto, particular incidência nos concelhos de Montemor, Oliveira do Hospital e Figueira da Foz $\left({ }^{49}\right)$. A produção era, porém, insuficiente para o consumo. Um dos factores explicativos residia no facto de o tubérculo não se dar bem em algumas zonas, caso dos Campos de Coimbra. Em 1862 o Governador Civil do distrito de Coimbra informava que a batata "que em alguns Districtos constitue a principal alimentação do povo, nem é d'uso tão frequente neste, nem a sua cultura se accomoda muito bem com a natureza dos terrenos, principalmente nos Campos de Coimbra" $\left(^{50}\right)$.

$\left({ }^{46}\right)$ David Justino, ob. cit., vol. I, pp.42-43.

$\left({ }^{47}\right)$ Suplemento ao Guarda-Livros Moderno, t. I, Lisboa, 1818, p. 32. (Citado por David Justino, cit., p. 42).

$\left({ }^{48}\right)$ João Lourenço Roque, Classes populares no distrito de Coimbra no século XIX (1830-1870). Contributo para o seu estudo, dissertação de doutoramento policopiada, t. 1, Coimbra, 1982, p. 412.

$\left({ }^{49}\right)$ Sobre a produção da batata no distrito de Coimbra na segunda metade do século XIX, bem como o significado social do seu consumo ver: João Lourenço Roque, ob.cit., vol. I, t I., pp. 38-39, 265-266 e 411-412.

$\left({ }^{50}\right)$ Cfr. Lourenço Roque, ob., cit., pp. 38-39. 
Uma das zonas de eleição da cultura da batata continuava, entretanto, a ser a parte mais litoral do distrito. Vejamos o que escreve Rui Cascão sobre o cultivo desta planta nos finais do século XIX em Buarcos. "A batata assumia em Buarcos o aspecto de uma cultura hortícola e deveria desempenhar aí um papel de relevo na alimentação dos rurais. A exemplo do que acontecia em relação ao conjunto do concelho, onde era considerada o segundo alimento mais comum logo a seguir ao pão de milho" [...] "Desenvolvia-se particularmente bem no "terreno da montanha da parte occidental do Cabo Mondego", o que originava tubérculos de "optima" qualidade e proporcionava elevados índices de produtividade, a ponto de render 25 a 30 sementes, mesmo sem o recurso ao estrume. A boa qualidade das batatas produzidas nas duas abas da Serra da Boa Viagem é confirmada por outra fonte (O Tribuno Popular, $\mathrm{n}^{\circ} 1964,28$ de Novembro de 1874) que as considera talvez as melhores do paiz, premiadas nas exposições em que têm comparecido, distinguindo-se as batatas da Mortinheira" $\left({ }^{51}\right)$. Saliente-se que a Murtinheira é um lugar que fica na encosta litorânea da Serra da Boa Viagem, pertencente à actual freguesia de Quiaios.

9. Como decorre do que ficou escrito, a batata chegou ao actual concelho da Figueira da Foz, concretamente a Quiaios, couto integrado no senhorio territorial do mosteiro de Santa Cruz e jurisdicional da Universidade, na primeira metade do século XVII.

A nova planta encontrou um habitat favorável nas encostas da Serra da Boa Viagem e nos areais da Gândara: solos adequados, vastos espaços incultos, homens que na labuta esforçada e perseverante pela sua sobrevivência não hesitavam em arriscar novos hábitos alimentares. Estes homens desenvolveram ao longo

$\left.{ }^{51}\right)$ Rui de Ascensão Ferreira Cascão, Permanência e mudançaem duas comunidades do litoral: Figueira da Foz e Buarcos entre 1861 e 1910, dissertação de doutoramento policopiada, vol. I, Coimbra, 1989, pp. 265-266. 
de três séculos uma luta sem tréguas, tentando resistir à partilha com os Crúzios do fruto que crescia debaixo da terra e que por vezes conseguiam ocultar nos campos intercalados de pinhais.

Os dados disponíveis até ao momento levam-nos a pensar que o tubérculo se confinou durante quase três séculos aos areais da Gândara, onde terá constituído cultura principal na faixa mais litorânea (dunas do quaternário) e cultura associada a outras nas terras mais férteis do interior (nas areias do plioceno), bem como na serra, caso de Brenha.

A batata viria a descer aos campos do Baixo Mondego nos inícios do século XIX, em tempos de miséria e carestia, para substituir o milho e o trigo. Outro motivo que levou os homens de Verride a cultivar batatas foi a expectativa de não terem de partilhar a colheita com o mosteiro de Santa Cruz. A batata não viria, porém, a tornar-se uma cultura dos terrenos húmidos e por vezes alagados do Baixo Mondego, solos mais adequados para a cultura do milho e do arroz.

Estas são as conclusões a que chegamos após a exploração de documentaçã̃o de natureza judicial do núcleo documental do mosteiro de Santa Cruz de Coimbra. Um conhecimento mais alargado da história da cultura da batata nesta região até ao século XIX passará naturalmente pela exploração dos núcleos documentais de outros senhorios, bem como de outra documentação que conserve rastos do cultivo desta planta e da forma como ela se integrava na economia das comunidades locais.

A documentação senhorial, fundamentalmente a relativa a conflitos, apesar da sua importância, é uma fonte indirecta para o estudo do significado económico e social da introdução e difusão da cultura da batata. Ela é, entretanto, muito esclarecedora sobre o elevado peso da tributação que recaía sobre esta cultura. Com efeito, a exigência da entidade senhorial de uma parte da produção que oscilava entre 22,5\% (dízimo + ração de oitavo) a 35\% (dízimo + ração de quarto) tornava a cultura não rentável para o agricultor. 
Este obstáculo, diríamos poderoso obstáculo, terá necessariamente de ser tido em conta como factor explicativo da lenta difusão desta cultura, ao lado de outros de ordem técnica e mental.

$\mathrm{Na}$ zona que constitui objecto do nosso estudo a batata foi, segundo pensamos, fundamentalmente cultura de solos pobres e alimento servido também na mesa dos mais débeis, homens que a levaram consigo quando partiram à procura de vida melhor, homens da condição daqueles que Van Gogh expressivamente retratou no quadro "Os comedores de batatas".

M. Margarida Sobral Neto 


\title{
APÊNDICE
}

\section{DOCUMENTO 1}

\author{
"Carta citatoria" enviada pelo Juiz privativo do Mosteiro de Santa Cruz \\ de Coimbra ao Juiz do couto de Quiaios em 16 de Março de 1643.
}

Dom Joaõ Per graça de Deos Rey de Portugual e dos Alguarves daquem e dalem mar em Africa Senhor de guine e da conquista naveguaçam comersio de etiopia Arabia persia e das indias etc. A todos os corregedores provedores ouvidores juizes justiças officiaes e pessoas de meus reinos e senhorios a que esta minha carta citatoria e in forma for apprezentada e o conhecimento della com direito pertencer e seu cumprimento se pedire requerer fassovos a saber em como a mim, e ao meu conservador por mim com Alsada nos estudos e Universidade da minha muy nobre e sempre leal cidade de Coimbra inviaram dizer per huma sua petiçam o Viguairo Geral apostoliquo da Congreguaçam dos Coneguos Regulares de Sancto Augostinho deste Reino de Portugual com poderes de Prior do Mosteiro de Santa Crus da dita cidade de Coimbra e geral de sua congregaçam Cancellario da dita Universidade e os mais Religiozos do dito Mosteiro que eles queriam demandar diante o dito meu conservador as pessoas declaradas no Rol junto por the nam quererem paguar a setima parte das batatas que haviaõ nas terras do dito couto de que eles suplicantes eram direito senhorio, e tinham obriguaçam de the paguar a setima parte de todas as novidades na forma do foral; pello que me pediam em fim e concluzam da dita sua petiçam the mandasse passar carta para os sobreditos serem citados e suas molheres pelo sobredito, e receberiam justiça e merce etc. e no Rol que com a dita petiçam se offereceo se continha o seguinte: Joaõ de figueiredo sessenta alqueires, Joaõ de Britto sincoenta, Pedro fernandes da Cangosta des, Antonio Ribeiro quarenta, Pero fernandes de baixo sincoenta, Pero Rodrigues trinta, Dominguos fernandes filho de Bento fernandes vinte, Joaõ fernandes trinta, Francisco Rodrigues barreguido quarenta, Manuel Cassam outenta, Antonio fernandes da Azinhaga vinte, Bento fernandes quarenta, Antonio jorge trinta, fernaõ Gonsalves des, Dominguos Gaspar Baluarte vinte, Antonio Domingues Bero quarenta, Pero jorge vinte, Francisco dis genro de Pero jorge quarenta, Manuel joaõ vinte, Pero da Cangosta sesssenta, Dominguos gonsalves genro de Bento fernandes vinte, Manuel Affonso trinta, Manuel Rodrigues o moço vinte, Antonio fernandes do cazal des, Antonio vâz perneiro quarenta, Antonio fernandes dos junqueiros vinte, Antonio 
vâz da terra de Santa Marinha trinta, Pero gonsalves trinta, Joaõ jorge vinte, Dominguos fernandes trinta, Joaõ Guaspar quarenta, Thome Duarte des, segundo que tudo esto assim e tam copiozamente se continha e era contheudo e declarado na petiçam dos ditos suplicantes e em seu petitorio, e no dito Rol que com ella se offereceo e eu vendo o que elles em ella me assim dizer e pedir enviaram e por bem dos privilegios e liberdades dados e outorguados pellos Reis passados meus antecessores e por mim confirmados á dita Universidade de que todos os ditos supplicantes e seu mosteiro guozam como disso notoriamente consta por bem dos quais privilegios e na forma de seus estatutos o dito meu conservador soomente he o seu juis competente de todas suas cauzas civeis e crimes em que forem autores ou Reos. Mandei se passasse a carta que pediram e portanto para movidas minhas justiças e quada hum a que direitamente pertenser foi passada a prezente pella qual vos Mando que tanto que prezentada vos for sendo primeiro passada pella chansellaria da dita Universidade a cumpraes, e guardeis e na forma della com delligencia por nossos officiaes de justiça fareis citar a todos e a quada huma das pessoas atras declaradas e a suas molheres para que do dia que citados forem a tres dias primeiros seguintes paressam per sy ou seus bastantes procuradores na dita cidade de Coimbra perante o meu Conservador e em seu juizo competente e audiencia em dia, e horas della que forem costume fazer em segundas e sestas feiras de cada somana as tardes dias nam fereados, a estarem a direito com hos supplicantes e seu procurador que os querem obriguar e demandar a cada hum delles pellas quantias de alqueires de Batatas que se declarar em suas addições atras que se estam devendo e sam obriguados paguar de sete hum das terras que possuem de que os ditos supplicantes e seu mosteiro sam direito senhorio, sendo certo que sendo citados e passado o dito termo nam vindo as suas revelias seram por tais avidos para o que dito he termos e autos judiciaes atee final sentença, e sendo cazo que os sobreditos, ou algum delles se escondam, amovem ou abzentem e de sy nam queiram dar copia a fim de em suas proprias pessoas nam averem de ser citados, constandonos delles por summaria informaçaõ ou por fee de algum de nossos officiaes de justiça o seram na pessoa de hum familiar de caza de quada qual ou no juizo mais cheguado a quem seria declarado o cazo das citações o dia do aparecer atras e, de huma maneira e outra que citados forem se passara certidam nas costas desta em modo e maneira que faça fee para elle meu Conservador todo ver e no cazo proceder com inteiro compprimento de direito e justiça. Ouvindosse lá com embarguos ao inteiro comprimento desta em parte ou no todo vos mando delles nam tomeis conhecimento de qualquer materia que sejam sem embarguo dos quais que loguo remetereis ao juizo competente do dito meu conservador o inteiro comprimento 
della na maneira em que vai nella dado tera e avera em todo seu devido effeito. O que huns e outros assi comprireis com deligencia e al nam fareis sob as penas dos encontos e as mais destas teudas e nova reformaçam etc. Dada na dita cidade de Coimbra aos dezasseis dias do mes de Março. El Rey nosso senhor o mandou pello Doutor Simaõ Zuzarte Themudo do seu dezembarguo, seu conservador com alsada nos estudos da Universidade desta nossa cidade. Anno do nasçimento de nosso senhor jesus Christo de mil seis centos quarenta e tres annos pagouse de asssinatura desta carta citatoria vinte reis e de feitio della cento e sessenta, e da distribuiçaõ seis reis, e se declara que os suplicados atras contheudos sam moradores no couto de quiaios, dia mes anno ut supra

Joaõ Zuzarte Themudo (assinatura autógrafa)

[À margem:] "Cumprasse quiaios 20 de março de 643 joam cassaõ juis"

(ANTT: Santa Cruz de Coimbra, maço 24)

\section{DOCUMENTO 2}

Carta enviada por um morador de Quiaios ao Prior do mosteiro de Santa Cruz de Coimbra.

Padre Dom Theotonio

Vossa Ciencia(sic) mandoume sitar pella reção das batatas façame caridade de naõ proceder contra mim porque quero pagar ao mosteiro a reção dellas e bem pudera escuzar de vir nesta Carta porque naõ ponho duvida a pagar ao mosteiro os seus direitos e mais coando tenho tantas obrigacoins senaõ ajudar en tudo o que puder e para o serviço de Vossa Ciencia estou sempre prestes o que Deus me guarde por largos e fellices annos para me encomendar mais quiaios deste seu leal cervo

Antonio Ribeiro (assinatura autógrafa)

(ANTT: Santa Cruz de Coimbra, maço 24) 


\section{DOCUMENTO 3}

Libelo apresentado pelo mosteiro de Santa Cruz de Coimbra contra produtores de batata de Quiaios.

Libello Deziam como Autores o Procurador Geral e mais Conegos do Real Mosteiro de Santa Crus desta Cidade de Coimbra contra o capitam Manoel Cardozo da Maia e sua mulher... [41]

Provariam que os Autores e seu Mosteiro sam Donatarios e senhorios directos de todo o lemite e couto de quiaios e suas fazendas rottas e por romper nas quais e ao dito couto o senhor Dom Manoel Rei deste Reino deu foral no anno de mil quinhentos e quattorze ordenado pellos titullos do Mosteiro e Inquiriçoins que fes tirar do qual os Reos e os mais moradores do dito coutto tinham inteira noticia e o conservavam e sempre conservaram em seu poder e cartorio publico da sua camera e concelho rezam porque sabem e devem saber o que elle dispoe e detremina //Provariam que pello dito foral que os Autore offeressem em poder dos Reos e no cartorio da sua camera e concelho heram os moradores do dito coutto e seu lemite obrigados a pagarem aos Autores e seu Mosteiro a ressam de sete hum de todas as novidades a saber o pam vinho linho alhos sebollas ervanços frutos e legumes e na posse da dita reçam se acham os Autores Ha des vinte trinta quarenta outenta sem e duzentos annos e muito mais tempo que ja excede a memoria dos homens no que não havia duvida e isto mesmo haviam de confessar os reos depondo alem do Dizimo por serem os Autores padroeiros da Igreja do dito Couto // Provariam que não obstante o referido e clauzullas do dito foral e posse dos Autores que nos termos de direito conservada em parte fazia nos reos obrigação total fabricavam estes e cultivavam varias sementeiras de batatas de que se alimentavam e utilizam suas cazas e familia como de outros quaisquer frutos e legumes de que de trinta e outo annos a esta parte não pagão aos Autores a dita Reçam de sete hum sendo como sam a vista do referido pessuidores de ma fee e devedores do dito Dizimo // Provariam que cada hum dos Reos recolhia de suas fazendas hum anno por outro quinze alqueires das ditas Batatas das quais vinham e haviam de vir ao Mosteiro ainda mais de dois alqueires alem do dizimo que pertence aos Autores em rezam de lhe estar unida a Igreja do dito couto como tudo milhor na execussam da sentença se liquidara tanto em rezam da dita reçam como do Dizimo que deverem dos ditos trinta e outo annos vencidos pella prezente novidade de Sam Miguel proximo passado de mil setecentos e trinta //Provarião que as ditas Batatas as cultivam e fabricam os reos nas terras mais capazes de dar milho e outra qualquer novidade cuja mudança de fructo mudavam com 
o dollo e malicia de se izentarem da dita reçam e Dizimo sendo que he trevial em direito que quando em alguns predios se varia a sementeira disso mesmo que nelles se afruta se deve pagar cotta a que os ditos predios estam obrigados e mais quando todas as fazendas que de novo se abrirem pello dito foral estam obrigadas á dita reçam e Dizimo dos frutos que preduzirem // Provariam que os Autores assistiam distantes do dito couto sete legoas alem de que sempre the o prezente trouxeram a sua renda por Rendeiro rezam porque nunca tiveram noticia da falta de pagamento desta Reçam e Dizimo das ditas Batatas do que ao direito do Mosteiro não prejudicou nem podia prejudicar qualquer facto proprio ou omissão ou negligencia dos ditos Rendeiros sem expreço consentimento dos Reos e nem tacito se podia prezumir // Provariam que alem de que consta o Mosteiro dos Autores senão pode considerar prescripçam alguma assim pello que fica referido como por serem Donatarios da coroa e terem a seu favor o privilegio da Igreja Romana como hera notorio sendo os antepessuidores dos Reos citados no anno de mil seiscentos corente e tres pella dita Reçam das Batatas dezistiram da acçam e se obrigaram ao pagamento dellas e continuaram como a seu tempo se mostraria a vista do que // Provaria que deviam os Reos ser condemnados a satisfazerem ao Mosteiro dos Autores o Dizimo e Reçam das Batatas que fabricarem nas terras do dito Couto a respeito das que lavrarem e cultivarem como na execussam da sentença se liquidara e isto deste trinta e outo annos a esta parte vencidos pellas novidades de Sam Miguel de mil stecentos e trinta sy mais deviam ser condemnados a continuarem no pagamento da dita Reçam e Dizimo na forma pedida annualmente e contra toda a omissam e negligencia de seus procuradores e prejuizos que lhe tenham cauzado pella dita omissam imploravm os Autores o Benefficio da Restituiçam in integrum de que gozavam et ita speratur = Fama publica //

(ANTT: Santa Cruz de Coimbra, maço 24)

\section{DOCUMENTO 4}

Acta da reunião da câmara de Quiaios, realizada em 19-12-1730

"O Juiz vereadores Procurador do Concelho do Coutto de Quiaios com as pessoas principais e mayor parte do Povo do dito coutto abaixo assignados fazemos saber que estando em acta de camera nos foi requerido pella mayor parte do dito povo se achava a citada Instancia do Muito Reverendissimo Padre Geral 
e mais Relligiozos do Real Mosteiro de Santa Crus da cidade de Coimbra pera fallar em hum libello que no Juizo da Conservatoria da Universidade queriam offerecer contra os moradores do dito coutto pera haverem de lhe pagar Renda das Batatas que nelle se lavrarem como a direitos senhoriais e por ser cauza que tocava com o dito povo queriam se ajustacem em camera o que sobre o referido se devia seguir em cujos termos se ajustou com o dito povo dezistirmos da dita cauza ou cauzas que no dito Juizo nos tiverem movido sobre a dita Renda e partilha das Batatas que se lavrassem em todas as fazendas deste concelho e assim pera a dita dezistencia constituimos e ordenamos por nossos Bastantes Procuradores aos Senhores Doutores Jorge Alvares Pereira e Silvestre de Magalhaens Brandam em poder de sobstaballecerem esta em hum e muitos procuradores e assim elles como cada hum dos ditos sobstaballecidos poderem requerer o termo ou termos da dita cauza que no dito Juizo nos tiverem movido os ditos Religiozos sobre a partilha das Batatas assignando os ditos termos com todas as condiçoens necessarias na forma do pedido nos libellos das ditas cauzas que de tudo confessamos pera o que lhe consedemos todos os poderes em direito nacessarios assim aos ditos nossos Procuradores como a cada hum dos sobstaballecidos e em firmeza de tudo abrigamos nossas pessoas e bens e mandamos passar esta que assignamos Quiaios em camera dezanove de Dezembro de mil setecentos e trinta annos"...

(Documento assinado pelo escrivão, Juiz, Procurador, capitãoManuel Cardozo e por mais 46 moradores)

\section{(Original)}

(ANTT: Santa Cruz de Coimbra, maço 24) 